Jurdimas (Jurnal Pengabdian Kepada Masyarakat) Royal

Vol. 3 No. 2, Juli 2020, hlm. 155 - 162

DOI: https $/ /$ doi.org/10.33330/jurdimas.v3i2.664

ISSN 2622-3813 (Online)

Available online athttps:/jurnal.stmikroyal.ac.id/index.php/jurdimas

\title{
BUDIDAYA LELE TERPAL SEBAGAI ALTERNATIF PENINGKATAN KESEJAHTERAAN BURUH PABRIK DI DUKUH REJOSARI
}

\author{
Yordan Gunawan $^{1^{*}}$, Tareq Muhammad Aziz Elven ${ }^{1}$ \\ ${ }^{1}$ Fakultas Hukum, Universitas Muhammadiyah Yogyakarta \\ email: yordangunawan@umy.ac.id
}

\begin{abstract}
Located at the foot of Mount Merbabu, Dukuh Rejosari was bestowed with beautiful scenery, cool weather and fertile land for farming such as coffee, tea, corn and tobacco. Regrettably, these have yet been maximally utilized by the locals because of their busy work as laborers who depend on wages. This is compounded by the very strict working hours that leave workers no time to utilize the blessing as additional income. In dealing with this situation, breeding catfish using tarpaulin method is likely the most appropriate alternative solution for the locals to earn more income without having to leave their main job as factory workers. This is possible as the catfish cultivation using tarpaulin method is effortless and does not consume much time to manage it. Moreover, with the annual increase in demand for catfish consumption in the surrounding regions as well as competitive selling prices (ranging from IDR14,000 to IDR17,000 per kilogram) making tarpaulin cultivation of catfish solution for the locals in Dukuh Rejosari. The method used in this service was socialization by providing outreach and training from the catfish cultivation expert. The result shows that villagers are enlightened to have a new source of income in the midst of busyness working as laborers.
\end{abstract}

Keywords: catfish cultivation; economic empowerment; dukuh rejosari

\begin{abstract}
Abstrak: Berlokasi di kaki gunung Merbabu, Dukuh Rejosari dianugerahi dengan pemandangan yang indah, cuaca yang sejuk, dan lahan yang subur untuk bercocok tanam seperti kopi, teh, jagung, dan tembakau. Namun hal belum dimanfaatkan secara maksimal oleh para penduduk dikarenakan kesibukan mereka sebagai pekerja buruh harian yang bergantung pada upah pabrik. Hal ini diperparah dengan jam kerja yang sangat padat membuat para pekerja tidak memiliki waktu lebih untuk memanfaatkan lingkungan sebagai tambahan penghasilan. Dalam menghadapi situasi tersebut, pengembangbiakan ikan lele dengan menggunakan terpal merupakan solusi alternatif yang paling tepat guna memberi para penduduk penghasilan lebih tanpa harus meninggalkan pekerjaan utama mereka sebagai buruh pabrik. Hal ini dimungkinkan karena budidaya lele terpal sangat mudah dilakukan dan tidak memerlukan banyak waktu untuk merawatnya. Juga, dengan peningkatan tahunan permintaan ikan lele konsumsi di daerah sekitar serta harga jual yang kompetitif (berkisar Rp. 14.000,- - Rp. 17.000,- per kilogram) menjadikan budidaya ternak lele terpal sebagai alternatif paling ideal untuk memberikan tambahan penghasilan kepada masyarakat Dukuh Rejosari. Metode yang digunakan adalah metode sosialisasi dengan memberikan pelatihan dari pembudidaya lele terpal berpengalaman. Hasil dari kegiatan ini yaitu masyarakat mendapatkan kesempatan untuk membentuk sumber pendapatan baru ditengah-tengah kesibukan bekerja sebagai buruh pabrik.
\end{abstract}

Kata kunci: budidaya ikan lele; peningkatan ekonomi; dukuh rejosari 
Jurdimas (Jurnal Pengabdian Kepada Masyarakat) Royal

Vol. 3 No. 2, Juli 2020, hlm. 155 - 162

DOI: https $/ /$ doi.org/10.33330/jurdimas.v3i2.664

ISSN 2622-3813 (Online)

Available online athttps://jurnal.stmikroyal.ac.id/index.php/jurdimas

\section{PENDAHULUAN}

Boyolali dikenal sebagai salah satu kabupaten yang memberikan kontribusi cukup tinggi terhadap produksi ikan nasional, khususnya ikan lele. Direktorat Jendral Perikanan Budidaya (DJPB) pada bulan Maret 2019 menegaskan bahwa Kampung Lele di Boyolali dapat memproduksi 37-ton ikan lele per hari yang mampu memasok pasokan ikan ke Yogyakarta, Semarang dan daerah-daerah lainnya di provinsi Jawa Tengah. Namun demikian, DJPB melihat bahwa pasokan ikan di daerah Jawa Tengah masih belum terpenuhi bila hanya bergantung pada Kampung Lele tersebut. Boyolali masih menghadapi kekurangan 140 juta ekor benih ikan setiap tahunnya untuk dapat menutupi kekurangan pasokan per tahunnya. Untuk itu, hal ini menjadi peluang bisnis bagi penduduk Boyolali lainnya untuk dapat ikut membantu memasok pasokan ikan air tawar di provinsi Jawa Tengah.

Dalam program ini, mitra pengabdi adalah masyarakat dukuh Rejosari yang pada dasarnya dikenal luas sebagai masyarakat yang aktif. Namun, semenjak masuknya pabrik-pabrik ke daerah kecamatan Gladagsari, masyarakat mulai berangsur-angsur beralih dari petani agraris menjadi buruh pabrik. Akan tetapi, luasnya lahan pekarangan yang dimiliki oleh masyarakat belum dimanfaatkan secara optimal. Masih terdapat lahan kosong yang belum dimanfaatkan oleh warga baik untuk bercocok tanam ataupun pemanfaatan lahan yang lainnya. Mayoritas pekerjaan masyarakat dusun Rejosari sebagai buruh juga menjadikan salah satu faktor kurangnya pemanfaatan lahan pekarangan yang dimiliki. Hal tersebut dikarenakan jam kerja masyarakat telah banyak dihabiskan di pabrik, sehingga masyarakat kurang memiliki waktu untuk memanfaatkan lahan pekarangannya. Berdasarkan hal tersebut, kami melihat adanya potensi untuk memanfaatkan potensi alam yang tersedia berupa lahan pekarangan masyarakat agar memiliki nilai guna dan nilai tambah. Salah satu program yang kami jalankan sebagai upaya pemanfaatan lahan pekarangan masyarakat dusun Rejosari adalah "Budidaya Ternak Lele Terpal".

Penggunaan metode kolam terpal untuk budidaya ikan lele pertama kali ditemukan dan diuji coba oleh Bapak Mujarob, seorang petani di Bekasi-Jawa Barat, pada tahun 1999. Hal tersebut dilakukan untuk dapat memberikan inovasi budidaya agar lebih praktis dan hemat biaya. Kolam terpal yang dibuat dibawah tanah memiliki keunggulan suhu yang lebih stabil serta memudahkan proses pasca panen.

Tujuan dari program pengabdian masyarakat ini adalah untuk meningkatkan perekonomian masyarakat di dukuh Rejosari dengan melakukan kegiatan usaha ternak lele menggunakan media terpal. Dalam hal ini, lahan tidak terpakai yang terdapat di pedukuhan akan dimanfaatkan dengan baik guna meningkatkan penghasilan penduduk setempat. Beberapa persoalan yang dihadapi oleh mitra guna merealisasikan program pengabdian masyarakat ini ialah kurangnya pehamanan tentang beternak lele menggunakan media terpal. Disamping itu, diperlukannya pelatihan dan pendampingan yang komprehensif dalam merelealisasikan program persoalan tersebut.

Program serupa sudah banyak dilakukan di berbagai tempat seperti (Dwiyanto, B. S. \& Jemadi, 2014); (Firdaus, Maharani, \& Hafsaridewi, 2017); dan (Negara, I Ketut W.N. \& Pebriani, Dewa A.A, 2017), namun ke- 
Available online athttps:/jurnal.stmikroyal.ac.id/index.php/jurdimas

banyakan adalah untuk mengem-bangkan usaha budidaya ikan lele terpal yang sudah ada di tempat tersebut. Berbeda dengan program ini, meskipun ada beberapa individu yang telah melakukan budidaya ikan lele di Dukuh Rejosari, namun mayoritas penduduk masih terpaut akan pekerjaan sehari-hari sebagai buruh, disamping adanya permintaan besar pasokan ikan lele di daerah Boyolali dan sekitarnya.

Manfaat yang diharapkan akan didapatkan oleh masyarakat Dukuh Rejosari atas program ini ialah peningkatan perekonomian masyarakat dengan pemanfaatan lahan tidak terpakai untuk beternak lele dengan menggunakan media terpal, mengingat mayoritas mata pencaharian masyarakat Dukuh Rejosari yaitu sebagai buruh pabrik yang memiliki sedikit waktu di rumah. Target yang diharapkan dari terlaksananya programprogram kegiatan ini antara lain agar masyarakat Dusun Rejosari mengetahui bagaimana cara mengelola lahan di pekarangan mereka secara optimal dengan program ternak lele dan meningkatkan hasil penjualan dengan bantuan media sosial sebagai alat pemasaran dalam rangka meningkatkan taraf hidup masyarakat setempat.

Dalam pendahuluan dapat diuraikan gap analysis (masalah, persoalan, atau kebutuhan pokok) dalam masyarakat berkaitan dengan target luaran, dan tujuan pengabdian masyarakat.

\section{METODE}

Pelaksanaan kegiatan sosialisasi dilaksanakan dari mulai tanggal 14 Januari sampai 14 Februari 2020 bertempat di kediaman Bapak P. Margono di Dukuh Rejosari, desa Ngadirojo, kecamatan Gladagsari, kabupaten Boyolali-Jawa
Tengah. Pelaksanaan kegiatan pengabdian masyarakat ini dibantu oleh mahasiswa KKN 147 Universitas Muhammadiyah Yogyakarta dan dilakukan dengan tahap awal yaitu identifikasi masalah serta kendala dalam hal budidaya ternak lele dengan menggunakan metode terpal.

Kendala tersebut tidak diselesaikan secara langsung atau simultan, melainkan dengan upaya penyelesaian secara bertahap untuk masing-masing keluarga yang ada di dukuh Rejosari. Responden yang kami dapat adalah sejumlah 15 kepala keluarga yang dari 2 kepala keluarga yang sudah menggeluti budidaya ternak lele dalam skala kecil. Setelah masalah teridentifikasi, selanjutnya adalah melakukan analisis masalah tersebut dan mencari solusi yang tepat untuk menyelesaikannya. Dilakukan pula analisis terhadap kebutuhan masyarakat dukuh Rejosari. Hasil dari analisis ini akan menjadi acuan terhadap kemungkinan dilakukannya budidaya ikan lele terpal secara masif.

Selanjutnya, hal yang dilakukan adalah sosialisasi tentang hasil analisis tersebut kepada masyarakat dukuh Rejosari jika hasil penemuannya adalah memungkinkan untuk melakukan budidaya ikan lele dengan menggunakan metode terpal. Pada tahap ini juga, masyarakat dukuh Rejosari akan diberikan pelatihan mengenai metode terpal pada budidaya ikan lele. Selanjutnya, masyarakat diberikan pelatihan-pelatihan lanjutan seperti pelatihan kewirausahaan, pelatihan pemasaran dan promosi, serta pelatihan dasar-dasar teknologi dan informasi. Dengan pelatihan-pelatihan ini, diharapkan masyarakat dapat mendapatkan cukup pengetahuan untuk menindak lanjuti dan mengembangkan budidaya ikan lele terpal tersebut agar berkelanjutan (Haditomo, 
Available online athttps:/jurnal.stmikroyal.ac.id/index.php/jurdimas

Pambudi dan Sudaryono, 2015).

Pada tahap selanjutnya, pendampingan kepada masyarakat dilakukan guna mengetahui perkembangan yang terjadi sejak sosialisasi dan pelatihan diberikan. Kemudian, evaluasi dilakukan guna mengetahui kendala-kendala yang ditemui selama pelaksanaan kegiatan tersebut.

\section{PEMBAHASAN}

Meskipun masyarakat dukuh Rejosari pada awalnya kurang menyanggupi usulan untuk memulai budidaya ternak ikan lele dengan menggunakan metode terpal, namun setelah dilakukan diskusi intensif bersama Kepala dukuh, tokohtokoh masyarakat, serta perwakilan pemuda desa, masyarakat akhirnya menerima baik usulan tersebut.

Setelah dilakukannya kajian mendalam berdasarkan hasil observasi dan diskusi dengan pihak masyarakat, pengabdi menyimpulkan beberapa faktor yang dapat mendukung serta menghambat realisasi budidaya ternak ikan lele terpal ini. Hal-hal yang mendukung dapat dilakukannya budidaya ikan lele dengan menggunakan metode terpal di dukuh Rejosari adalah lingkungan desa sekitar yang terletak di kaki gunung Merbabu yang asri serta banyak lahan luas tersedia. Sedangkan persoalan yang dihadapi adalah aktivitas rutin kebanyakan masyarakat setempat yang memang sudah menjadi buruh tetap di pabrik-pabrik sekitar lingkungan, menjadikan masyarakat terkendala waktu untuk memulai budidaya ikan lele terpal tersebut.

Beberapa persoalan mitra membutuhkan kajian, pelatihan dan pendampingan yang komprehensif di waktu-waktu yang tepat dimana mereka tidak merasa lelah dan luang. Maka dari itu, solusi yang dapat dilakukan guna menghadapi situasi tersebut yaitu dengan memanfaatkan waktu libur di hari Sabtu dan Minggu dan/atau di hari-hari biasa pada malam hari.

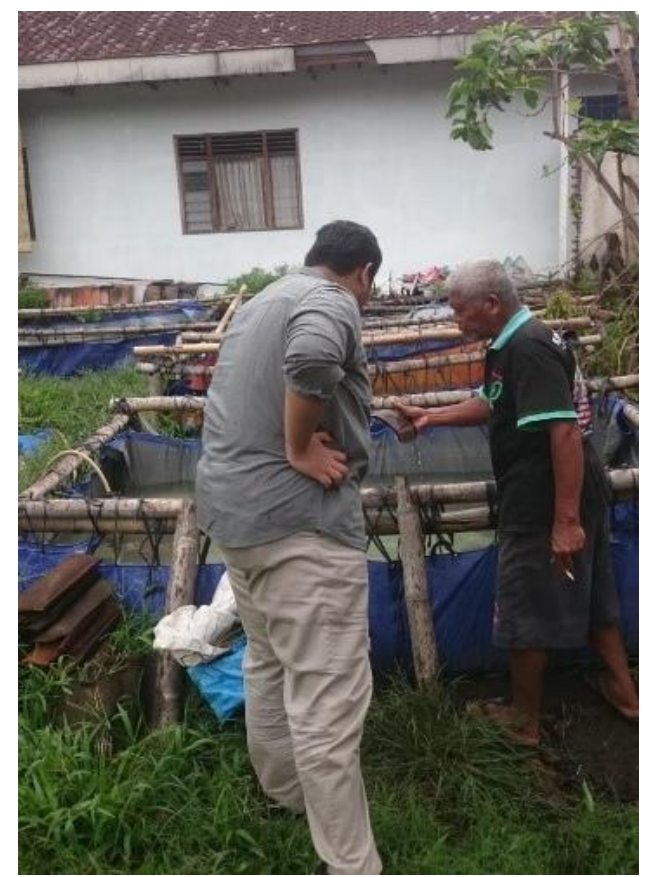

Gambar 2. Warga Setempat yang sudah beternak lele terpal

Setelah melakukan kajian permasalahan, dapat disimpulkan bahwa budidaya ikan lele terpal dapat menjadi solusi alternatif bagi masyarakat Dukuh Rejosari untuk mendapatkan penghasilan tambahan disamping melakukan kegiatan bekerja sehari-hari sebagai buruh pabrik. Hal ini dikarenakan budidaya ikan lele dengan menggunakan metode terpal tidak membutuhkan banyak waktu dan tenaga untuk mengurusnya, hanya diperlukan waktu sekitar 30 menit setiap harinya untuk mengamati perkembangan ikan lele serta memberi pakan. Disamping itu, terpal dapat dibersihkan sekurangkurangnya satu bulan sekali guna menjaga kualitas ikan lele tersebut (Manurung \& Babo, 2014). 
Jurdimas (Jurnal Pengabdian Ke pada Masyarakat) Royal

Vol. 3 No. 2, Juli 2020, hlm. 155 - 162

DOI: https://doi.org/10.33330/jurdimas.v3i2.664

Available online athttps://jurnal.stmikroyal.ac.id/index.php/jurdimas

Guna memberikan pengetahuan kepada masyarakat dukuh Rejosari tentang budidaya ternak lele terpal, kami mengundang Bapak Giyanto selaku pelaku bisnis ikan lele terpal yang sudah berpengalaman di Jawa Tengah. Tujuan dari kegiatan ini adalah untuk memberikan gambaran kepada masyarakat dukuh Rejosari tentang mudahnya melakukan budidaya ikan lele terpal bagaimana cara untuk mengurusnya (Sitio, Jubaedah \& Syaifudin, 2017). Selanjutnya, masyarakat dukuh Rejosari diberikan pelatihan tentang kewirausahaan yang disampaikan oleh Dosen Universitas Muhammadiyah Yogyakarta. Beliau menyampaikan materi seputar dasar-dasar berwirausaha dan bagaimana cara untuk memulai sebuah bisnis dan pengembangannya pada sektor budidaya ikan lele terpal (Riska, Primyastanto, \& Abidin, 2015).

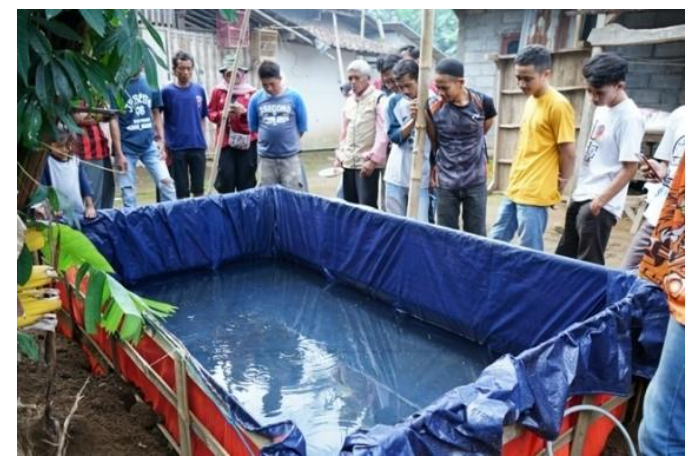

Gambar 3. Sosialisasi Budidaya Ternak Lele Terpal

Dalam menghadapi zaman modern ini, pun kami juga memberikan kesempatan kepada masyarakat dukuh Rejosari untuk mendapatkan pelatihan seputar pemanfaatan media sosial bagi perkembangan bisnis. Hal ini disampaikan oleh saudara Tareq Muhammad Aziz Elven, S.H., kepada masyarakat dukuh Rejosari.

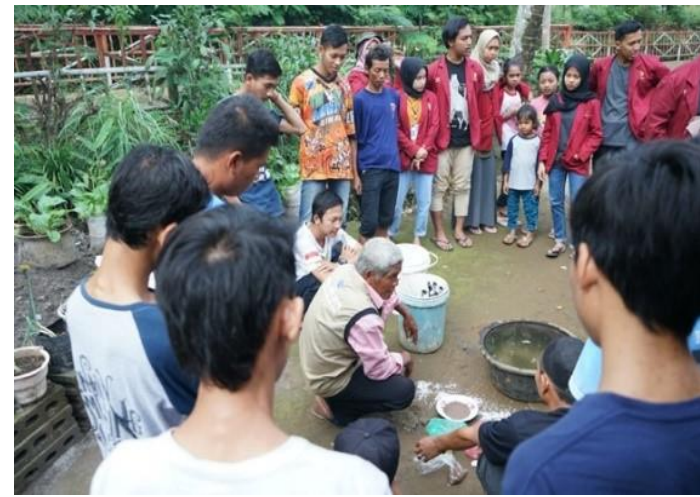

Gambar 4. Diskusi berasama Bapak Giyanto

Hal ini dilakukan guna meningkatkan kapasitas masyarakat untuk dapat memasarkan produk ikan lele nya melalui metode online, tidak hanya dengan metode offline atau dari mulut-ke-mulut. Harapannya, dengan menggunakan metode online ini yaitu meluasnya cakupan pelanggan ikan lele dukuh Rejosari tidak hanya di daerah sekitar dukuh saja, melainkan seluruh Kabupaten Boyolali hingga Provinsi Jawa Tengah. Selanjutnya, pelatihan ditutup dengan pelatihan manajemen pemasaran dan promosi yang disampaikan oleh Bapak Yordan Gunawan, S.H., Int.MBA., M.H., guna melengkapi pengetahuan masyarakat dukuh Rejosari akan berwirausaha.

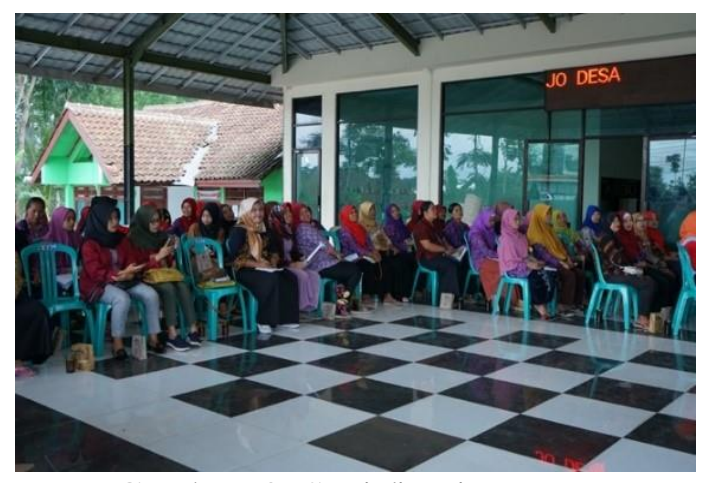

Gambar 3. Sosialisasi tentang Kewirausahaan

Metode pelatihan dilakukan untuk mengurangi persoalan kelembagaan dan sumber daya manusia terhadap mana- 
Available online athttps:/jurnal.stmikroyal.ac.id/index.php/jurdimas

jemen tata kelola, SDM, dan pemasaran produk ternak. Program-program pelatihan dalam pengabdian masyarakat dikembangkan dengan metode yang lebih sederhana, yaitu dengan menyelenggarakan sarasehan dan diskusi santai/ informal sehingga masyarakat tidak terlalu berat dalam menerima materi- materi pelatihan. Pelatihan yang dilakukan adalah pelatihan yang berkaitan dengan ruang lingkup budidaya baik bersifat regulatif, manajemen tata kelola, maupun komunikasi pemasaran.

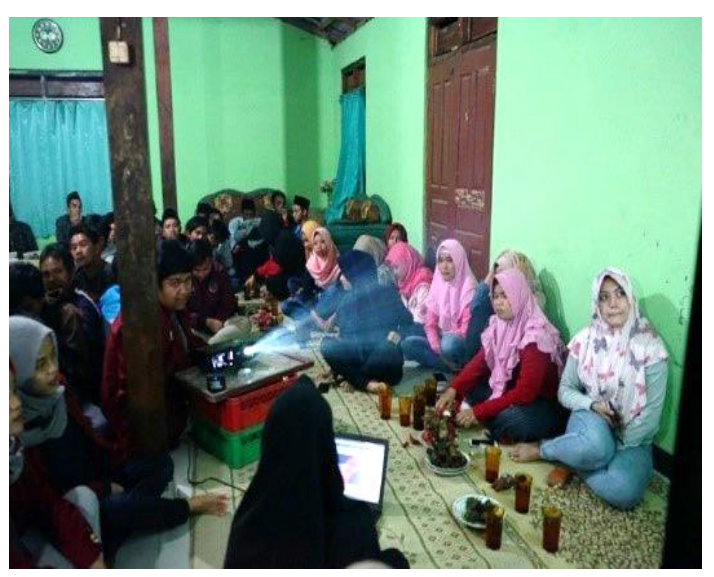

Gambar 4. Sosialisasi tentang Pemasaran Digital

Materi-materi pelatihan yang disampaikan mengambil beberapa kasus dan best practice pengelolaan budidaya ternak ikan lele, sehingga peserta pelatihan akan memperoleh gambarangambaran kasus dan strategi yang seharusnya dilakukan. Selain itu, juga sharing pengalaman merupakan syarat untuk dapat meningkatkan kreativitas dan inovasi masyarakat dan menjadi penentu pelaksanaan kegiatan dalam menciptakan masyarakat yang mandiri kompetitif berdaya saing (Widjajanti, 2011). Metode pelatihan dengan diskusi informal bertujuan untuk mendorong partisipasi dan perhatian peserta yang lebih intens.
Pelaksanaan pendampingan kepada warga berupa monitoring dilakukan sebagai salah satu bentuk pertanggungjawaban pengelolaan program yang telah dijalankan. Pendampingan tersebut meliputi evaluasi terkait pengelolaan ternak lele sekaligus memberikan arahan kepada masyarakat terkait bagaimana mekanisme pengelolaan yang baik. Selanjutnya, pendampingan juga ditujukan untuk memecahkan permasalahan yang dihadapi oleh masyarakat ketika mengelola budidaya ternak lele. Pengelolaan budidaya ternak lele diserahkan kepada masyarakat dengan penanggungjawab yang telah dipilih sebelumnya. Masing-masing kolam lele memiliki penanggungjawab tersendiri. Penanggungjawab kolam lele pertama adalah Bapak Margono selaku Kepala Dusun Rejosari dan penganggungjawab kolam lele kedua adalah Bapak Shodiq selaku Karang Taruna Tunas Karya. Adanya penanggungjawab pengelola ternak lele bertujuan sebagai pihak perantara yang akan berkomunikasi secara langsung dengan tim pengabdi sekaligus melaporkan perkembangan terkait per minggu (Muhammad, \& Andriyanto, 2013). .

\section{SIMPULAN}

Budidaya ternak ikan lele dengan menggunakan metode terpal merupakan alternatif yang paling tepat sebagai sarana ekonomi bagi masyarakat untuk mendapatkan tambahan penghasilan disela waktu yang sedikit terutama bagi masyarakat dukuh Rejosari untuk menghasilkan penghasilan tambahan disamping bekerja sebagai buruh pabrik industri.

Disamping itu, untuk memulai budidaya ternak lele tidaklah sulit dan memakan biaya yang cukup ringan, biaya 
perawatan yang tidak begitu mahal serta tidak memerlukan waktu banyak menjadi kelebihan dari modal usaha ini bagi masyarakat. Hal ini didukung juga dengan banyaknya lahan yang tidak terpakai di sekitar Dusun yang dapat dimanfaatkan oleh masyarakat untuk memulai usaha ini.

Disamping itu, evaluasi pada usaha diperlukan secara berkala dan dapat dilaksanakan secara bersama-sama agar hasil ternak ikan lele dari dukuh Rejosari dapat diterima baik oleh pasar. Branding serta Marketing pun akan mudah dilakukan secara bersama-sama.

\section{UCAPAN TERIMA KASIH}

Ucapan terima kasih kepada masyarakat dukuh Rejosari yang telah mendukung kegiatan ini. Kepada Bapak P. Margono selaku Kepala Dusun yang telah menerima kami dengan baik dan sangat mendukung pengabdian masyarakat ini. Kepada Bapak Giyanto selaku pelaku bisnis ikan lele terpal yang sudah berpengalaman di Jawa Tengah yang berkenan untuk membagikan ilmu serta pengalamannya kepada masyarakat dukuh Rejosari. Kepada Lembaga Penelitian, Pengembangan dan Pengabdian kepada Masyarakat (LP3M) Universitas Muhammadiyah Yogyakarta (UMY). Kepada selurh Tim Pengabdian Serta semua pihak yang terlibat dalam program pengabdian masyarakat ini.

\section{DAFTAR PUSTAKA}

Sitio, Maru Hariati Friska, Jubaedah, Dade \& Syaifudin, Mochamad (2017). Kelangsungan Hidup dan Pertumbuhan Benih Ikan Lele (Clarias sp.) pada Salinitas Media yang Berbeda. Jurnal Akuakultur Rawa Indonesia 5(1), 85-93.

Muhammad, Willy Nofian \& Andriyanto, Septyan. (2013). Manajemen Budidaya Ikan Lele Dumbo (Clarias gariepinus) di Kampung Lele, Kabupaten Boyolali, Jawa Tengah. Media Akuakultur 8(1), 65.

Dwiyanto, B. S. \& Jemadi. (2014). Wirausaha Kelompok Usaha Budidaya Pembesaran Lele. Jurnal MAKSIPRENEUR 4(1), 421.

Firdaus, M., Maharani, H., \& Hafsaridewi, R. (2017). Usaha Budidaya Ikan Lele (Clarias sp.) pada Kawasan Minapolitan "Kampung Lele" Kabupaten Boyolali. Buletin Ilmiah "MARINA" Sosial Ekonomi Kelautan dan Perikanan 3(2), 7989.

Manurung, Usy N. \& Babo, Desmianti. (2017). Budidaya Ikan Kolam Terpal di Kampung Kendahe II, Kecamatan Kendahe, Kabupaten Kepulauan Sangihe. Jurnal Ilmiah Tatengkorang 1, 46-47.

Haditomo, A.H.C., Pambudi, L.T., \& Sudaryono, A. (2015). Budidaya Ikan Lele dalam Kolam Terpal di DAK Rumah Lantai 2 Sebagai Solusi Pemanfaatan Lahan Wilayah Perkotaan. Jurnal Info 17(3), 112-114.

Riska, Fiya Fajriya, Primyastanto, Mimit, \& Abidin Zainal. (2015). Strategi Pengembangan Usaha Budidaya Ikan Lele (Clarias sp.) pada Usaha Perseorangan "Toni Makmur" Dikawasan Agropolitan Desa Kauman, Kecamatan Ngoro, Kabupaten Jombang, Jawa Timur. Jurnal ECSOFiM 3(1), 51-54.

Negara, I Ketut W.N. \& Pebriani, Dewa 
Jurdimas (Jurnal Pengabdian Kepada Masyarakat) Royal

Vol. 3 No. 2, Juli 2020, hlm. 155 - 162

ISSN 2614-7912 (Print)

DOI: https://doi.org/10.33330/jurdimas.v3i2.664

ISSN 2622-3813 (Online)

Available online athttps:/jurnal.stmikroyal.ac.id/index.php/jurdimas
A.A. (2017).
Manajemen
Perikanan 8(1), 38-43.
Pembesaran Lele Dumbo Clarias
Widjajanti, Kesi. (2011). Model sp. Melalui Inovasi Kolam Terpal di Desa Pakisan Kabupaten Buleleng. Samakia: Jurnal Ilmu Pemberdayaan Masyarakat. Jurnal Ekonomi Pembangunan 12(1), 25. 